\title{
Coronary fistula resembling patent ductus arteriosus
}

\author{
Fístula coronário-cavitária simulando persistência do ductus arteriosus
}

Ricardo Nilsson SGARBIERI, Francisco F. MOREIRA NETO, Fabiano Ferreira VIEIRA, Tatiana Maia J. U. BARBOSA

RBCCV 44205-659

\section{Abstract}

A 14-year-old girl, presenting with heart failure and a continuous murmur, similar to that of a patent arterial duct, was investigated using echocardiogram and cardiac catheterization revealing a left to right shunt throught a coronary artery fistulae between the first septal branch and the right ventricular outflow tract. The patient was submitted to surgery, occluding the anomalous branch by the suturing of its orifice in the right ventricular outflow tract, under cardiopulmonary bypass.

After the operation, cardiac catheterization revealed complete occlusion of the fistula without any residual shunt or compromise to the coronary circulation.

In seven years of follow-up the patient is completely free of symptoms.

Descriptors: Fistula, heart. Fistula, coronary circulation. Coronary vessels anomalies, surgery.

\section{Resumo}

Criança, do sexo feminino, 14 anos de idade, apresentando quadro clínico de insuficiência cardíaca e sopro, suspeitandose de persistência do canal arterial. Durante a investigação diagnóstica, foi realizado ecocardiograma e coronariografia que evidenciou uma fístula entre a artéria coronária esquerda e o ventrículo direito. A paciente foi submetida a tratamento cirúrgico, sendo o ramo anômalo abordado por meio de ligadura direta do seu orifício, com auxílio de circulação extracorpórea.

A coronariografia pós-operatória não evidenciou fluxo pela fístula e demonstrou fluxo normal pelos demais ramos da artéria coronária esquerda. No seguimento de sete anos, a paciente encontra-se livre de sintomas.

Descritores: Fístula, coração. Fistula, circulação coronária. Anomalias dos vasos coronários, cirurgia.

Work performed in the Medical School of Triângulo Mineiro.

Cardiac Surgery Department.

Correspondence address: Dr. Ricardo Nilsson Sgarbieri. Head of Cardiac Surgery Department of the do Medical School of Triângulo Mineiro. Av: Getúlio Guarita s/n. Uberaba,

Minas Gerais.

Phone: (34) 3318.5682 or 3318.5282

Fax: (16) 632.9205. (34) 3312.7183.

E-mail: rsgarbieri@uol.com.br 


\section{INTRODUCTION}

Coronary-chamber connections are considered to be a rare finding, the majority of which have a congenital etiology [1-3].

Their incidence, in adults submitted to cardiac catheterization is from 0.1 to $0.2 \%$ [2], and they can present diverse origins, courses and drains [3].

Around $50 \%$ of the coronary connections originate from the right coronary artery. The majority drain to the right heart chambers or to the pulmonary artery and its branches $[1,3,4]$.

Coronary connections are easily approached by surgical treatment, which aims at occluding the fistula without prejudicing adequate perfusion of the myocardium.

In this report we describe a case of a coronary-chamber connection clinically simulating the persistence of the arterial canal in a 14-year-old child.

\section{Case Report}

A 14-year-old girl was examined in our service complaining of dyspnea after effort, tiredness palpitations during rest and edema of the lower extremities which had started one month previously.

A physical examination presented a regular general state, she was acyanotic, anicteric, afebrile, tachydyspneic and without edema of the lower limbs. Palpation of the precordia presented with fremitis in the left parasternal region. On auscultation there was a continuous murmur at pulmonary and accessory aortic focuses, with hyperphonesis of B2. The heart frequency was 96 beats per minute and the arterial pressure was 100 x $70 \mathrm{mmHg}$.

A chest radiograph presented with an increase in the cardiac area at the detriment of the right ventricle accompanied by bulging of the pulmonary artery. The electrocardiogram presented with sinusal rhythm with overload of the right ventricle.

An echocardiogram was performed to confirm the diagnosis of patent arterial duct. However, the echocardiogram did not evidence a patent arterial duct, instead suggesting a hypothesis of a coronary-chamber connection. Thus, an angiography was performed which did not demonstrate a patent arterial canal, but the cardiac catheterization evidenced a large connection between the first septal branch of the left coronary artery and the outlet of the right ventricle, without any other associated anomalies (Figure 1a).

In the face of this clinical state and the complementary examinations, surgical treatment was indicated.

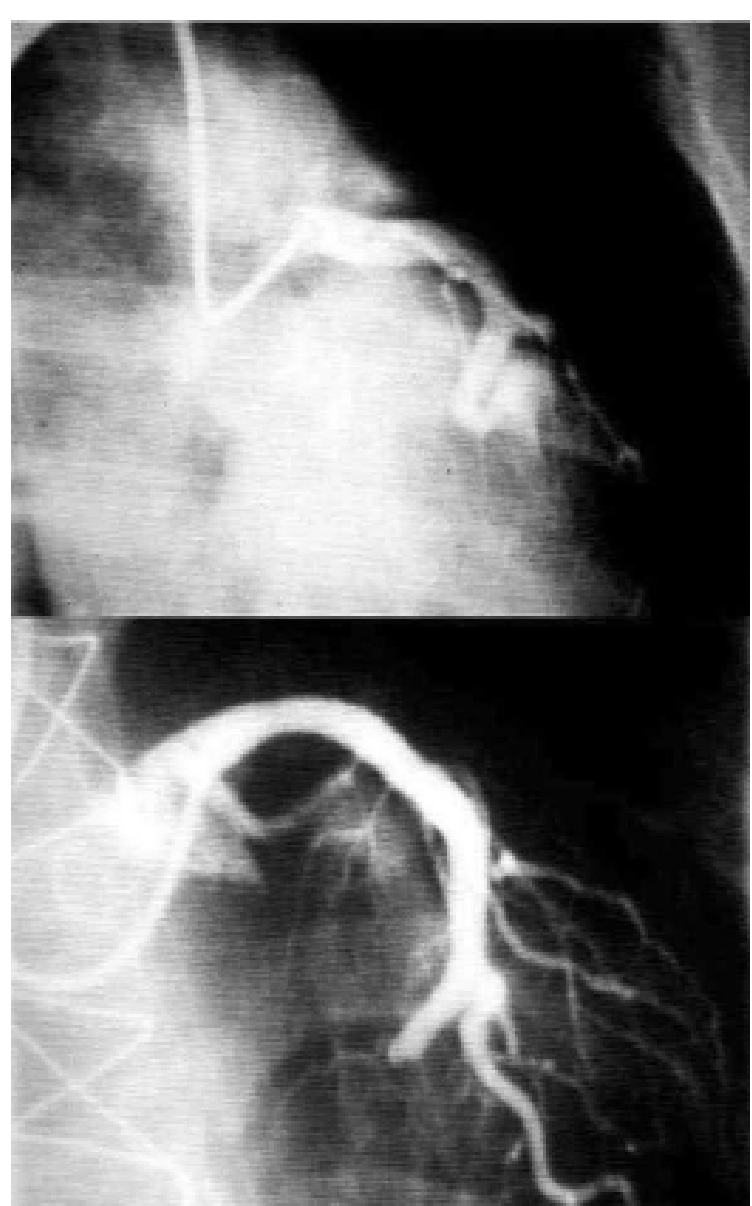

Fig. 1 - Cardiac catheterization pre- (a) and post-operative (b), demonstrating the existence of a connection between the left coronary artery and the right ventricle and, subsequently its occlusion

A median sternotomy was performed and after cardiopulmonary bypass was established. The outlet of the right ventricle was opened identifying the orifice of the connection (Figure 2a) which was occluded by direct suturing (Figure $2 \mathrm{~b}$ ). Then a direct suturing of the ventricle was performed.

There were no complications in the post-operative period. Ten days after surgery, another cardiac catheterization was performed that confirmed complete occlusion of the connection (Figure 1b), with adequate perfusion of the other branches of the left coronary artery.

In a seven-year follow-up period the patient continues completely free from adverse symptoms.

\section{COMMENTS}

The majority of the coronary connections has a congenital etiology $[1,3]$, and can be associated with other cardiac anomalies [5]. However, other etiologies have been 
described such as the consequence of endomyocardial biopsies of the right ventricle after transplantation or after percutaneous coronary angioplasty [6].

a)

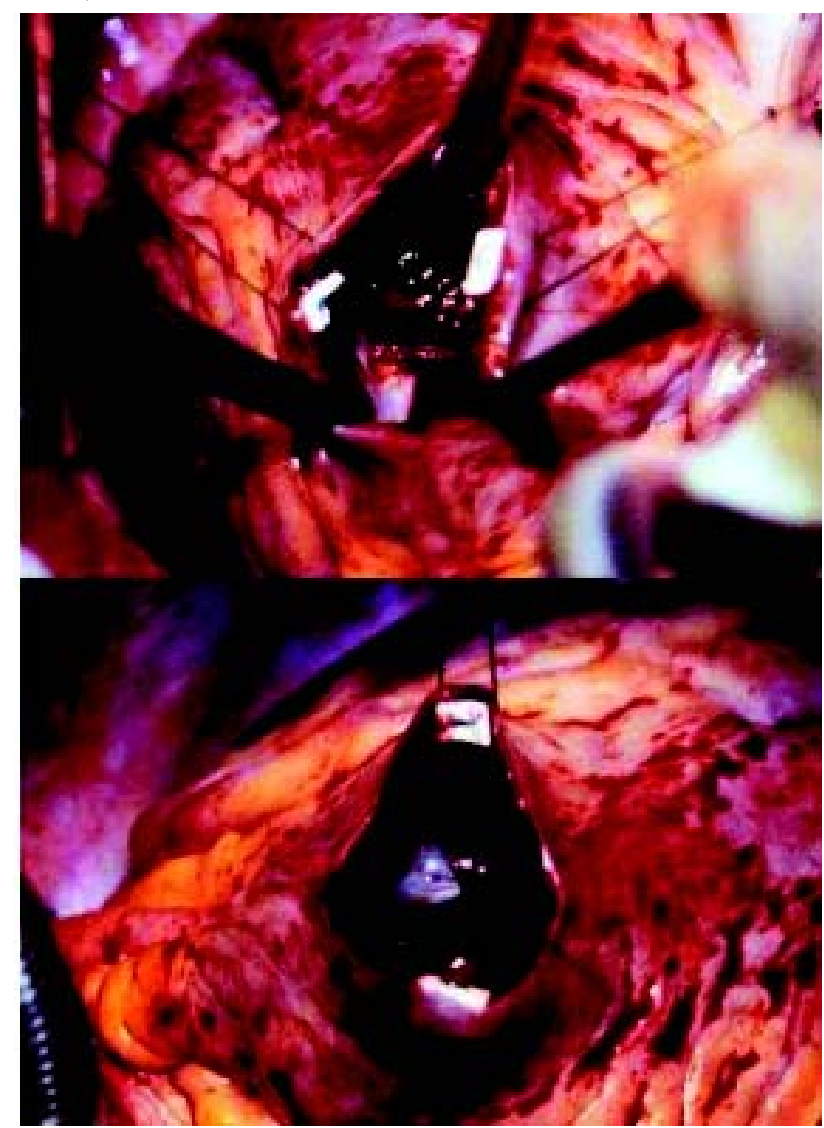

b)

Fig. 2 -Operative photographs. Right ventriculotomy, identification of the orifice of the fistula (a) and its occlusion (b)

Around $50 \%$ of the coronary connections originate from the right coronary artery $[1,3]$. The majority of them drain to low-pressure chambers, that is, to the right side of the heart $[1,3-6]$. Coronary connections draining to the left ventricle are extremely rare.

Physiopathologically, it is believed that congenital fistulas originate during the embryological development of the heart. It is suggested that partial patency of the embryonary myocardial sinusoids lead to an abnormal development of the Thebesian system, giving origin to coronary connections.

The natural history is not well known. The majority of reported cases are of adults who were originally asymptomatic and after evolve with complications. The symptoms depend on the magnitude of the shunt, to which cavity it is draining and the age of the patient $[1,3,4,6\}$. Faced with these variables there may exist a great range of signs and symptoms. In the majority of cases the shunt has little hemodynamic significance, with the coronary fistula is only discovered in an investigation of an atypical cardiac murmur [1,4-6]. When it is symptomatic, these connections can present with myocardial ischemia, due to the existence of coronary outflow $[3,4,6]$, cardiac insufficiency $[1,3,4,6]$, endocarditis, rupture, arrhythmias and in some rare cases, pulmonary hypertension. It has been reported that the symptoms and complications increase with age $[1,3]$.

The most important complementary examination for diagnosis is the coronary arteriography [2-6]. The chest radiograph may demonstrate an increase in the right heart chambers if the shunt is significant [4], as in this case. The electrocardiogram may demonstrate an overload of the right chambers or ischemic alterations, if this is the predominant syndrome [3-5]. The echocardiogram may identify alterations in the right cardiac chambers, depending on the size of the shunt. Recently, the intracoronary doppler ultrasound has been used in an attempt to measure the hemodynamic importance of fistulas.

The treatment of this disease is still controversial in the literature, especially when the surgical approach of asymptomatic patients is concerned [1,3]. Some researchers question if this entity has physiopathologic significance, or if it is only a normal variation owing to a prominent Thebesian system. The clinical treatment aiming at alleviating the symptoms, with the use of betablockers, calcium channel blockers and nitrate, have their defenders in publications [6]. However, the indication of surgery in patients with congestive heart failure, angina, recurrent endocarditis $[3,4,6]$ or traumatic fistulas (accidental or iatrogenic) seems to be consensus. Others defend surgical treatment in asymptomatic patients $[1,5]$, including children [1], owing to the possible complications and knowing that the operation is technically simple and has low morbid-mortality rates.

In this case, the surgical choice arose because the patient presented signs and symptoms of congestive heart insufficiency owing to a non-negligible shunt.

The operation can be performed with or without cardiopulmonary bypass [4]. The surgical treatment aims at selective closure of the connection, without prejudicing the normal coronary circulation [4]. Recently, transesophageal echocardiography has been used to locate the fistula during the intra-operative period when cardiopulmonary bypass is not used.

An alternative technique, which has been widely discussed in publications, is percutaneous embolization of the fistula with coils [5].

Considering the reviewed literature, we believe that surgical treatment of this disease should be extensively utilized. 


\section{BIBLIOGRAPHIC REFERENCES}

1. Godart F, Rey C, Cajot MA, Gutierrez R, Francart C, Vaksmann $\mathrm{G}$ et al. Intérêt du ballon largable en silicone dans la fermeture des fistules coronarocardiaques. Arch Mal Coeur Vaiss 1997; 90:611-6.

2. Dakik HA, Farmer J, Kleiman NS. Images in cardiovascular medicine: fistula between left main, left anterior descending and pulmonary arteries. Circulation 1998; 97:2091-2.

3. Silveira WL, Ostoa DE, Jatene MB, Barbero-Marcial M, Oliveira SA, Jatene AD. Tratamento cirúrgico de fístulas congênitas da artéria coronária. Arq Bras Cardiol 1995; 65:31-5.
4. Reul RM, Cooley DA, Hallman GL, Reul GJ. Surgica treatment of coronary artery anomalies: report of a 37 and a half year experience at the Texas Heart Institute. Tex Heart Inst J 2002; 29: 299-307.

5. Mavroudis C, Backer CL, Rocchini AP, Muster AJ, Gevitz M. Coronary artery fistulas in infants and children: a surgical review and discussion of coil embolization. Ann Thorac Surg 1997; 63:1235-42.

6. Wolf A, Rockson SG. Myocardial ischemia and infarction due to multiple coronary - cameral fistulae: two case reports and review of the literature. Cathet Cardiovasc Diagn 1998; 43:179-83. 